\title{
Fabrication of Reverse Locking Mechanism for Four Wheeler
}

\author{
Mr. Thrivikram Prabhu ${ }^{1}$
}

\section{Ashith kumar ${ }^{2}$, Gaurav Bangera ${ }^{3}$, Mohammed Anish ${ }^{4}$, Moorthy Sagar Ashok ${ }^{5}$}

${ }^{1}$ Sr. Assistant professor, Dept. of Mechanical Engineering, Alva's Institute of Engineering and Technology, Karnataka, India.

${ }^{2345} 8^{\text {th }}$ Sem, B.E Mechanical Engineering, Alva's Institute of Engineering and Technology, Karnataka, India.

\section{Abstract}

At the point when a typical vehicle is proceeding onward a slanted way in a substantial rush hour gridlock or in the event that it is halted on the slant and then suddenly started, it tends to move in reverse. This can cause an accident with the vehicle just behind. In the normal running of a vehicle we have to perform three tasks at the same time i.e. disengaging the hand brake, releasing the clutch and at the same time accelerating the car. It can prove to be difficult for a novice driver. To solve this problem, we make use of the free-wheel, which is attached to the differential. The motion of the freewheel is controlled by the solenoid operated valve and the free-wheel is restricted in reverse direction.

Keywords:- Differential gear, Free-wheel, solenoid operated valve.

\section{INTRODUCTION}

A differential is a device, usually, employing gears, capable of transmitting torque and rotation

through three shafts.A vehicle's wheels rotate at different speeds, mainly when turning corners. The differential is designed to drive a pair of wheels while allowing them to rotate at different speeds.When cornering, the inner wheel needs to travel a shorter distance than the outer wheel, so with no differential, the result is the inner wheel spinning and/or the outer wheel dragging, and this results in difficult and unpredictable handling, damage to tires and roads, and strain on the entire drive train.

\section{A. Objectives}

- The major objective of our project is to prevent these types of accidents with some simple and economical means.

- To prevent the unexpected reverse motion of an Automobile under gradients and mountain roads.

- To protect the heavy load vehicle drivers and fellow Pedestrians from disastrous accidents occurring due to Loss of control and improper handling of equipment.

- To ensure the safety of the driver and vehicle on inclined grounds.

- To increase the life of brake shoe and to reduce the fuel consumption.

\section{METHODOLOGY}

To overcome the problem, a freewheel is used. This freewheel is engaged with the help of hand lever and is coupled with the bevel gear of the differential. The motion of the free-wheel is restricted in reverse direction. So, when the vehicle is moving in the forward direction the free-wheel also moves in the forward direction. But when the vehicle is moving in reverse direction the free-wheel restricts the reverse motion. Hence, the accidents can be avoided. Also, the free-wheel doesn't have to be disengaged for the vehicle to move in the forward direction. It can move in forward direction without 
any problem. To move in the reverse direction the free-wheel has to be disengaged. To ensure whether the free-wheel is engaged or disengaged a display mechanism can be used.

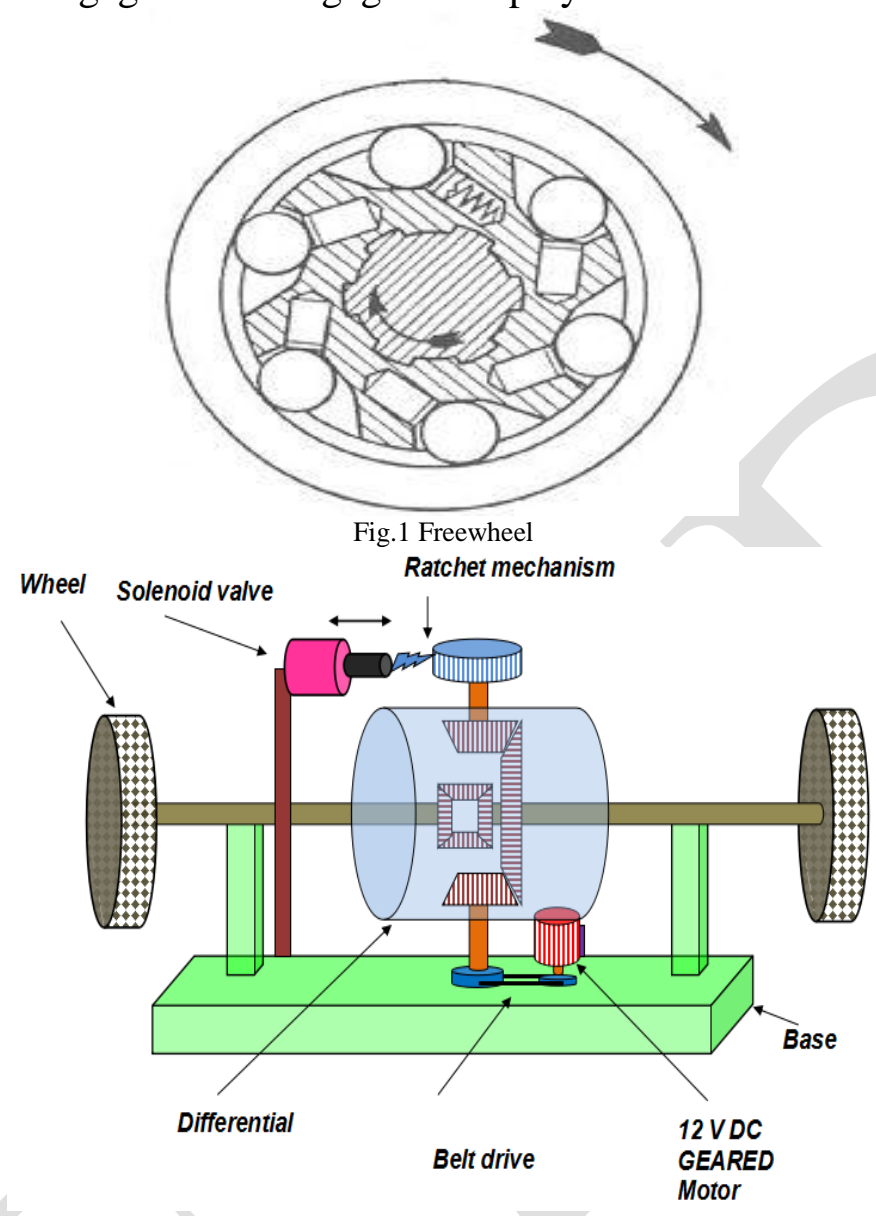

\section{DESIGN CALCULATION}

\section{A. DESIGN OF DC MOTOR}

Power of motor $=17 \mathrm{~N}-\mathrm{m} / \mathrm{s}$

$\mathrm{Rpm}$ of motor $=1800 \mathrm{rpm}$

Output rpm $=24 \mathrm{rpm}$

Power of motor $(\mathrm{P})=17$ watt

Power transmitted by shaft

$\mathrm{P}=2 \pi \mathrm{NT} / 60$

Where, $\mathrm{N} \rightarrow \mathrm{Rpm}$ of motor shaft $=24$

$\mathrm{T} \rightarrow$ Torque transmitted

$17=2 * \pi * 24 * \mathrm{~T} / 60$

$\mathrm{T}=6.76 \times 103 \mathrm{~N}-\mathrm{mm}$

We know that,

Dia of small pulley, D1 $=50 \mathrm{~mm}$

Dia of big pulley, D2 $=150 \mathrm{~mm}$

Ratio $=\mathrm{R}=1: 3$

Torque on pulley $=3 \times \mathrm{T}$

$=3 \times 6.76 \times 103$

$=20.280 \times 103 \mathrm{~N}-\mathrm{mm}$

$\mathrm{T}=$ Force $\times$ radius 
$20.280 \times 103=\mathrm{F} \times 75$

$\mathrm{F}=270 \mathrm{~N}$

B. DESIGN OF SPUR GEAR SHAFT.

SAE 1040 SAE (SOCIETY OF AUTOMOBILE ENGENEERING)

$10=$ Plain carbon steel

$40=0.4 \%$ of carbon

Torque transmitted by shaft,

$\mathrm{T}=\pi / 16 \times \tau \times \mathrm{d} 3$

Select permissible shear stress $(\tau)$ from design data book.

$\mathrm{T}=70 \mathrm{~N} / \mathrm{mm} 2$

Therefore, $20.28 \times 103=\pi / 16 \times \mathrm{d} 3 \times 70$

$\mathrm{D}=12 \mathrm{~mm}$.

We select dia. Of shaft $=12 \mathrm{~mm}$.

Taking factor of safety for shaft $=1.6$

D actual for shaft $=12 \times 1.6=19.2 \mathrm{~mm}=20 \mathrm{~mm}$.

\section{GEAR DESIGN.}

A pair of Spur gears mounted consists of 20 teeth on both the pinion and 40 teeth on gears.

$\mathrm{Ft}=($ fo $\times \mathrm{Cv}) \mathrm{b} \times 3.14 \times \mathrm{m} \times \mathrm{y}$

(REFER MACHINE DESIGN BY R.S. KHURMI \& J.K.GUPTA pg.no 880)

$\mathrm{f}_{\mathrm{og}}=\mathrm{f}_{\mathrm{op}}=$ Allowable static stress $=85 \mathrm{~N} / \mathrm{mm} 2$

$\mathrm{v}=$ Peripheral speed in $\mathrm{m} / \mathrm{sec}$.

$\mathrm{V}=3.14 * \mathrm{D} * \mathrm{~N} / 60$

$\mathrm{v}=3.14 \times \mathrm{m} \times \mathrm{T} \times \mathrm{N} / 60$

$\mathrm{v}=3.14 \times \mathrm{m} \times 40 \times 8 / 60$

$\mathrm{v}=16.74 \mathrm{~m}($ in $\mathrm{mm} / \mathrm{sec})$

$\mathrm{v}=0.0167 \mathrm{~m}(\mathrm{in} \mathrm{m} / \mathrm{sec})$

$\mathrm{Cv}=$ velocity factor

$\mathrm{Cv}=6 /(6+\mathrm{v})$

$\mathrm{Cv}=6 /(6+0.0167 \mathrm{~m})$

$\mathrm{m}=$ module

$\mathrm{y}=$ tooth form factor

Induced Tangential Force $(\mathrm{Ft})$

$\mathrm{Ft}=1000 \mathrm{PC}_{\mathrm{s}} / \mathrm{v}$

$\mathrm{Ft}=1000 \times 17 \times 1.25 / 4 \times 16.74=317.35 \mathrm{~N}$

$\mathrm{F}$ actual $=$ Ft $\times 1.2=317.35 \times 1.2=380.78 \mathrm{~N}$

The force applied by the motorise system on differential unit is $380.78 \mathrm{~N}$

5.2.3Tangential Force bearing capacity of bevel gear

$\mathrm{Wt}=($ fo $\times \mathrm{Cv}) \mathrm{b} \times 3.14 \times \mathrm{m} \times \mathrm{y}$

$\mathrm{Wt}=(85 \times 6 /(6+0.0167 \times 4)) 10 \times 4 \times 3.14 \times 4 \times(0.124-(0.684 / 20))$

$\mathrm{Wt}=3794.5 \mathrm{~N}=3795 \mathrm{~N}$

As Tangential Force bearing capacity of bevel gear is more than applied force thus design of spur gear is safe.

\section{CONCLUSIONS}

Our project helps in avoiding the reverse motion of the vehicle on the inclined roads and Ghats. Since no complex structures are used in our design, it can be easily use by novice drivers. Thus the mechanism can stop the vehicle from rolling back in hill roads. This would be more helpful for the 
DOI : https://dx.doi.org/10.26808/rs.ed.i8v3.04

International Journal of Emerging Trends in Engineering and Development

Issue 8, Vol.3 (April- May 2018)

Available online on http://www.rspublication.com/ijeted/ijeted_index.htm

ISSN 2249-6149

drivers to drive their cars comfortably in hilly roads and he can take off the car in the uphill without rolling back the car.

\section{V.REFERENCES}

I. Design Data Book(PSG) :- Freewheel design (7.93,7.94), Spring(7.100,7.101,7.105,1.10), Material Selection for spring(1.9), Shaft(PSG 7.21,7.72)

II. Design of Machine Elements by V B Bhandari: - Springs (pg 389), Shaft Design (pg 323, $2^{\text {nd }}$ edition).

III. http://en.wikipedia.org/wiki/Freewheel

IV. Theory of machines by R.S Khurmi \& Gupta :- Differential gear of an automobile( $\operatorname{Pg} 441,13^{\text {th }}$ edition) 